\title{
Comparative Study on Application of Fireproof Polystyrene Board and Traditional Polystyrene Board in External Wall Insulation of Building
}

\author{
Jiawei YAO, Zhaoming HOU \\ School of Architecture \\ Dalian Minzu University \\ Dalian, China \\ e-mail: yaojw656@163.com,hzm@dlnu.edu.cn
}

\author{
Yishu YAO \\ College of Architecture and Art \\ Dalian University of Technology \\ Dalian,China \\ e-mail:conan187@163.com
}

\begin{abstract}
The use of fireproof thermal insulation material in building external wall insulation system is of great significance. In this paper, through the research of three kinds of fireproof polystyrene insulation board in our country building market in recent years, the comparison and analysis with traditional polystyrene thermal insulation panel, proposes that building external wall thermal insulation material in the premise of satisfying the thermal insulation effect, also has good fire resistance performance, convenient construction, green environmental protection and economic feasibility, so that these new materials can be popularized in engineering, has the practical and historical significance, and thus promotes the progress and development of building energy saving technology in our country.
\end{abstract}

Keywords-external wall of building; heat-preservation materials; fire-proof polystyrene; application contrast

\section{INTRODUCTION}

In the building external wall insulation materials, organic materials compared with in-organic materials have good insulation effect, but the fire performance is relatively poor. In practical engineering, the external wall thermal insulation material needs not only outstanding thermal insulation effect, but also good fire resistance performance, at the same time, it has perfect thermal insulation supporting system, convenient construction method, and can meet the needs of green environmental protection and economic feasibility. In recent years, the fire-retardant polystyrene board is more and more approved by the engineering, can make it widely used in engineering, has the realistic environmental benefits, economic and social benefits, will promote the progress and development of building energy saving technology [1-5]. In this paper, several new fire retardant polystyrene insulation boards are compared and analyzed in order to achieve the application demonstration effect.

\section{TPS MODIFIED POLYSTYRENE ZHENJINBOARD}

The modified polystyrene zhenjin board is modified on the basis of the traditional EPS polystyrene board(Fig. 1). It is composed of thermosetting phenolic resin as coating solvent and red phosphorus as flame retardant. The flameretardant expandable polystyrene material has good flame retardant effect, it adopts interdisciplinary and cross-cutting technology to make each organic particle form an independent fire individual so as to partition heat conduction and flame propagation effectively, not only retains the traditional EPS polystyrene board has advantages of low thermal conductivity, good thermal insulation effect and light quality, but also overcomes the disadvantages of the traditional EPS polystyrene board flame etardant effect is poor, it is a better organic thermal insulation material with good performance, because its color is orange red, so called zhenjin board.

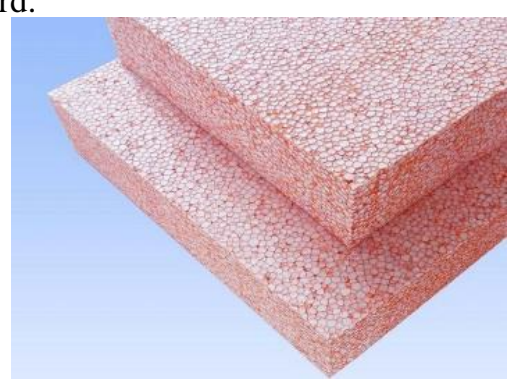

Figure 1. The modified polystyrene zhenjin board.

\section{A. Performance Characteristics of TPS Modified Polystyrene Zhenjinboard}

(1) The fire performance is excellent and the combustion performance is B1 to A2 level(Fig.2). When flame spray for 30 seconds, surface is only carbonized, has no smoke, no melting, and no irritant odor. After 30 minutes of flame spray, only the burned parts produce carbonation, the other parts are basically intact, so that the recurrence of burning can be avoided.

(2) Compared with other Aclass fire insulation materials, the thermal insulation performance is excellent, and the thermal conductivity is between $0.035-0.041$.

(3) Accord with ROHS testing standards, no harmful substances volatile, and do not produce decomposition and mildew, no pollution of the environment gas, can be recycled and reused, be good at environmental protection and energy saving.

(4) Have good physical properties, high compressive strength and good dimensional stability.

(5) The surface can be sprayed and plastered all kinds of stone coatings, forming insulation decorative board, fire prevention, insulation, decoration integrated solution, easy to construction, saving cost. 


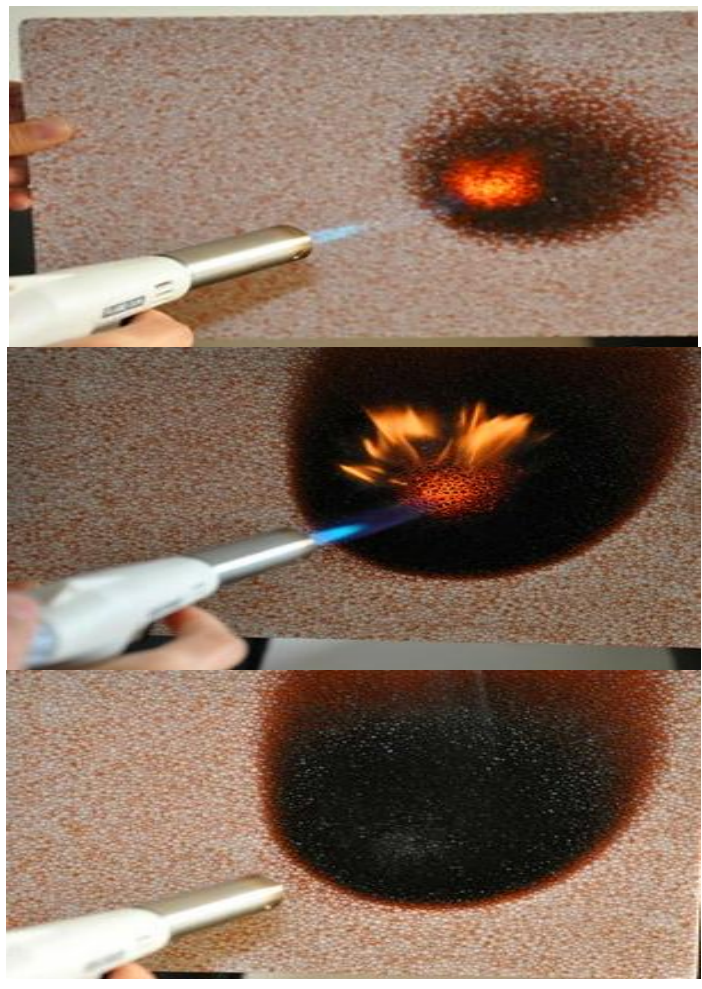

Figure 2. The fire performance is excellent.

B. Comparison of TPS Modified Polystyrene Zhenjinboard and Traditional EPS Polystyrene Board

Compared with the traditional EPS polystyrene board, TPS modified polystyrene zhenjin board has close insulation performance, which belongs to excellent thermal insulation and energy saving materials. The comprehensive performance of the two is not big, but the main difference is the combustion performance, the combustion performance of TPS modified polystyrene zhenjin board is obviously stronger than the traditional EPS polystyrene board, the combustion performance level can reach A2 and B1 level. See table 1 .

\section{AEPS SILICON POLYSTYRENE BOARD}

Aeps silicon polystyrene board is to pre - foaming the expandable polystyrene bead before treatment, and then heat the silicate, water, plasticizer, suspension stabilizer, polymerization catalyst, expansion agent and other preparation of the suspension in the mold for foaming. After the foaming, do the drying treatment, and then add foam board equipment for secondary heat foaming and molding, the combustion performance level can achieve A level and not burning(Fig.3).

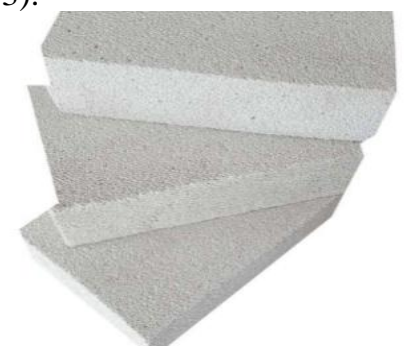

Figure 3. Aeps silicon polystyrene board.

\section{A. Performance Characteristics of Aeps Siliceous Polystyrene Board}

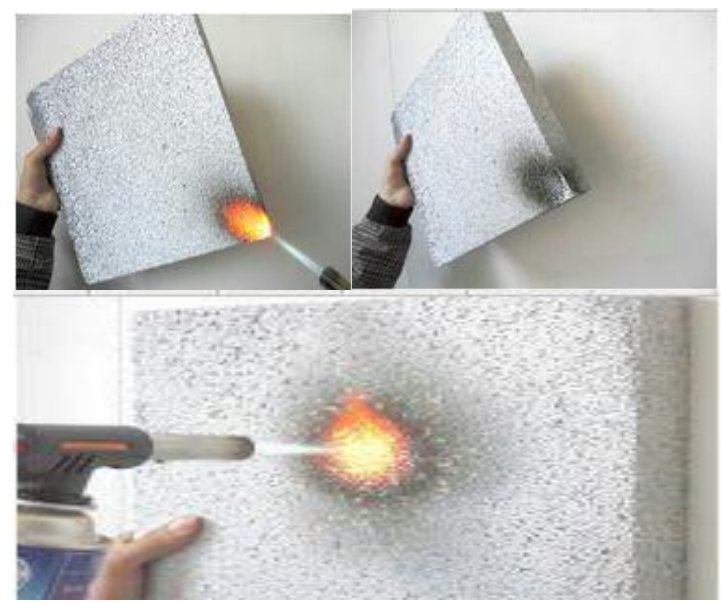

Figure 4. Not easy to burn in the state of open flame.

TABLE I.

PROPERTIES COMPARISON OF TPS MODIFIED POLYSTYRENE ZHENJINBOARDAND TRADITIONAL EPS POLYSTYRENE BOARD

\begin{tabular}{|l|l|l|}
\hline & \multicolumn{1}{|c|}{ Polystyrene board ( EPS ) } & Modified polystyrene zhenjinboard ( TPS ) \\
\hline Thermal conductivity(W/m.k) & $\leq 0.042$ & $0.035 \sim 0.041$ \\
\hline Density $\left(\mathrm{Kg} / \mathrm{m}^{3}\right)$ & $\geq 20$ & $\geq 35$ \\
\hline Compressive strength(MPa) & $\geq 0.1$ & $\geq 0.15$ \\
\hline Tensile strength(MPa) & $\geq 0.1$ & $\geq 0.15$ \\
\hline Dimensional stability(\%) & $\leq 0.3$ & $\leq 0.5$ \\
\hline Volumetric water absorption(\%) & $\leq 4.0$ & $\leq 1.4$ \\
\hline Combustion performance level & $\begin{array}{l}\text { B1, B2 level, Easy to burn, easy to } \\
\text { melt, and release a lot of smoke and } \\
\text { toxic gases when burning }\end{array}$ & $\begin{array}{l}\text { A2, B1 level, In case of fire, no burning and no drop, } \\
\text { smoke anesthesia and irritation }\end{array}$ \\
\hline The adhesion between the board and the mortar base & Easier to bond & Easy to bond \\
\hline
\end{tabular}


TABLE II.

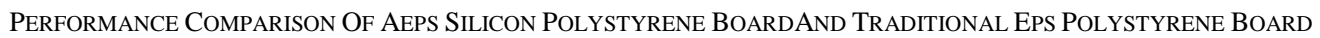

\begin{tabular}{|l|l|l|}
\hline & \multicolumn{1}{|c|}{ Polystyrene board ( EPS ) } & \multicolumn{1}{|c|}{ (AEPS)Siliceous polystyrene board } \\
\hline Thermal conductivity(W/m.k) & $\leq 0.042$ & $\leq 0.038$ \\
\hline Density $\left(\mathrm{Kg} / \mathrm{m}^{3}\right)$ & $\geq 20$ & $\geq 83$ \\
\hline Compressive strength(MPa) & $\geq 0.1$ & $\geq 0.4$ \\
\hline Tensile strength(MPa) & $\geq 0.1$ & $\geq 0.14$ \\
\hline Dimensional stability $(\%)$ & $\leq 0.3$ & $\leq 0.3$ \\
\hline Volumetric water absorption(\%) & $\leq 4.0$ & $\leq 3.3$ \\
\hline & $\begin{array}{l}\text { B1, B2 level ,Easy to burn, easy } \\
\text { to melt, and release a lot of smoke } \\
\text { and toxic gas }\end{array}$ & $\begin{array}{l}\text { A1, A2, B1 level ,In case of fire, no burning and no drop, } \\
\text { smoke anesthesia and irritation }\end{array}$ \\
\hline The adhesion between the board and the mortar base & Easier to bond & Easy to bond \\
\hline
\end{tabular}

TABLE III.

Performance Comparison Of "Hi-PoR" Nonflammable Eps BoardAnd Traditional EPs Polystyrene Board

\begin{tabular}{|c|c|c|}
\hline & Polystyrene board ( EPS ) & Hi-POR nonflammable EPS board \\
\hline Thermal conductivity(W/m.k) & $\leq 0.042$ & $\leq 0.039$ \\
\hline Density $\left(\mathrm{Kg} / \mathrm{m}^{3}\right)$ & $\geq 20$ & $\geq 31.8$ \\
\hline Compressive strength(MPa) & $\geq 0.1$ & $\geq 0.15$ \\
\hline Tensile strength(MPa) & $\geq 0.1$ & $\geq 0.14$ \\
\hline Dimensional stability(\%) & $\leq 0.3$ & $\leq 0.4$ \\
\hline Volumetric water absorption(\%) & $\leq 4.0$ & $\leq 1.0$ \\
\hline Combustion performance level & $\begin{array}{l}\text { B1, B2 level } \\
\text { Easy to burn, easy to melt, produce } \\
\text { smoke and toxic gases when } \\
\text { burning }\end{array}$ & $\begin{array}{l}\text { According to GB } 8624-2012 \text { standard test, the } \\
\text { combustion performance reaches A2 level. } \\
\text { In case of fire, no burning and no drop, smoke } \\
\text { anesthesia and irritation }\end{array}$ \\
\hline The adhesion between the board and the mortar base & Easier to bond & Easy to bond \\
\hline
\end{tabular}

(1) Not easy to burn in the state of open flame, and not spread in the flame condition, the combustion performance can reach B1, A2 to A1 level, and the safety is very high(Fig.4).

(2) The advantages of low thermal conductivity of traditional organic materials are reserved, which is slightly lower than the traditional EPS polystyrene board, and has good thermal insulation effect.

(3) The construction technology of the external insulation system of the traditional EPS polystyrene board is basically the same, has no increase in construction technology and the construction is convenient.

(4) Compared with the price of A level fireproof thermal insulation material, the price/performance ratio is higher, and there is a certain market prospect.

\section{B. Comparisonof Aeps Silicon Polystyrene Board and Traditional EPS Polystyrene Board}

The silicon polystyrene board improved the traditional EPS polystyrene board, continued its thermal insulation effect of good features, and increased the strength and durability of the plate, more importantly, greatly improved the combustion performance level. See table 2 .

\section{IV. "HI-POR" NONFLAMMABLE EPS BOARD}

"Hi-POR" nonflammable EPS board is a kind of no burning board developed by Korean enterprises(Fig.5). It is a product made of melamine formaldehyde resin with flame retardant composition on EPS particles. Melamineformaldehyde resinhas high curing rate, good heat resistance, and high tensile strength of film-covered. In addition, melamine formaldehyde resin contains a lot of flame retardant nitrogen elements, and phosphorus elements together flame retardant, has synergistic effect. Black pigment was added to the flame retardant liquid, and the flame retardant liquid of the flame retardant solution was completely covered with the naked eye. The main advantages of melamine after high temperature are halogenfree,low smoke, low toxicity, small impact on ecological animals and plants, conducive to environmental protection, both "environmental protection", "energy saving" and "fire prevention"[2].

\section{A. Performance Characteristics of "Hi-POR" Nonflammable EPS Board}

(1) The coating process can be finished on the general EPS beads, and the fire resistance of the film can be greatly 
improved after the film covering, the flame retardant grade can reach to $\mathrm{B} 1$ and the combustion performance to $\mathrm{A} 2$.

(2) Good insulation performance, light weight, simple construction, can be coated, can spray all kinds of stone paint to make integrated plate, and can achieve energy saving and fire protection acceptance standards.

(3) Production cost is lower than other existing A2 grade thermal insulation material production enterprise.

(4) The EPS foam material of B1 and B2 levels can be recycled and upgraded to a 2 grade, yielding benefit.

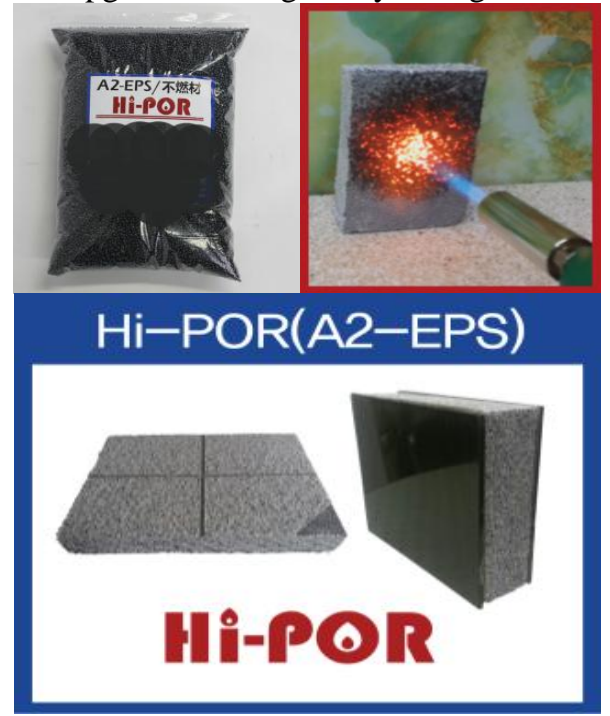

Figure 5. "Hi-POR" nonflammable EPS board.

\section{B. "Hi-POR" nonflammable EPS board compared with traditional EPS polystyrene board}

"Hi-POR" nonflammable EPS board compared with the traditional EPS polystyrene board, the thermal insulation performance and other properties are basically the same and slightly improved, it is important to improve the combustion performance of the plate. See table 3.

\section{SUMMARY}

Through the comparison and analysis of the three modified polystyrene EPS boards in markets, the three new materials retain the advantages of the traditional EPS foam board, such as "small thermal conductivity coefficient, large thermal storage coefficient, good thermal insulation effect, mature process, easy construction, safe and reliable", better thermal insulation effect than foam glass and inorganic active insulation mortar, higher strength than phenolic plate, rock wool and other materials, not absorbing water, light weight, not easy to fall off, and meet the insulation material A grade fire protection standards. Price, lower than A-grade flame retardant insulation materials similar products, higher price ratio. It is a kind of new material for building exterior wall insulation with good thermal insulation effect, high flame retardant performance and mature technology. It is suitable for the use of external wall insulation of civil buildings and industrial buildings, and the market has a broad prospect.

\section{ACKNOWLEDGEMENT}

This research was financially supported by Guidance Plan of Liaoning Natural Science Foundation (No:201602201 ); Special Funds for the Basic Research Business of the Central University (No:DC201502090302).

\section{REFERENCES}

[1] Zhu Chunling, Jiguangqi. Experimental study on fire resistance of polystyrene foam insulation materials.[J]. Building technique development, 2012,39(10):37-63.

[2] Wang yazhen, Mengshuang, Wang fengchao. Research progress of flame retardant for polystyrene.[J]. Guangzhou chemical industry, 2016, 44 (22):1-11.

[3] Yang Zhongwen, Liu Xiwen. Research progress of flame retardant technology of external wall polystyrene foam insulation materials.[J]. Shanghai plastics, 2016, 174(2):1-7.

[4] Yinming, Zhao min. Application of flame retardant silicone polystyrene board in roof engineering.[J]. China building waterproofing, 2016,23(12):33-36. 